\title{
Fuzzy logic model for the prediction of cement compressive strength
}

\author{
Sedat Akkurt ${ }^{\mathrm{a}, *}$, Gokmen Tayfur ${ }^{\mathrm{b}, 1}$, Sever Can $^{\mathrm{c}, 2}$ \\ ${ }^{a}$ Mechanical Engineering Department, Izmir Institute of Technology, 35430 Izmir, Turkey \\ ${ }^{\mathrm{b}}$ Civil Engineering Department, Izmir Institute of Technology, 35430 Izmir, Turkey \\ ${ }^{\mathrm{c}}$ Materials Science and Engineering Program, Izmir Institute of Technology, 35430 Izmir, Turkey
}

Received 22 September 2003; accepted 12 January 2004

\begin{abstract}
A fuzzy logic prediction model for the 28-day compressive strength of cement mortar under standard curing conditions was created. Data collected from a cement plant were used in the model construction and testing. The input variables of alkali, $\mathrm{Blaine}, \mathrm{SO}_{3}$, and $\mathrm{C}_{3} \mathrm{~S}$ and the output variable of 28-day cement strength were fuzzified by the use of artificial neural networks (ANNs), and triangular membership functions were employed for the fuzzy subsets. The Mamdani fuzzy rules relating the input variables to the output variable were created by the ANN model and were laid out in the If-Then format. Product (prod) inference operator and the centre of gravity (COG; centroid) defuzzification methods were employed. The prediction of 50 sets of the 28-day cement strength data by the developed fuzzy model was quite satisfactory. The average percentage error levels in the fuzzy model were successfully low (2.69\%). The model was compared with the ANN model for its error levels and ease of application. The results indicated that through the application of fuzzy logic algorithm, a more user friendly and more explicit model than the ANNs could be produced within successfully low error margins.
\end{abstract}

(C) 2004 Elsevier Ltd. All rights reserved.

Keywords: Modelling; Compressive strength; Fuzzy logic; Artificial neural networks

\section{Introduction}

Portland cement production is a complex process that involves the effect of several processing parameters on the quality control parameter of 28-day compressive strength. Examples for processing parameters are chemical parameters like the $\mathrm{C}_{3} \mathrm{~S}, \mathrm{C}_{2} \mathrm{~S}, \mathrm{C}_{3} \mathrm{~A}, \mathrm{C}_{4} \mathrm{AF}$, and $\mathrm{SO}_{3}$ contents in addition to the physical parameters like Blaine (surface area) and particle size distribution [1-3]. These factors are all effective in producing a single strength quantity of 28-day compressive strength. Such effects have been the subject of several different studies $[2,4,5]$. Particle size effect was studied by Osbaeck and Johansen [4] and later by Tsivilis et al. [6]. Clinker composition effect was investigated by Osbaeck [7], especially for the alkali effect. Radjy and Vunic [8] showed that the gel-space ratio can be used to

\footnotetext{
* Corresponding author. Tel.: +90-232-750-6523; fax: +90-232-7506505 .

E-mail addresses: sedatakkurt@iyte.edu.tr (S. Akkurt),

gokmentayfur@iyte.edu.tr (G. Tayfur), severcan@iyte.edu.tr (S. Can).

1 Tel.: +90-232-498-6280.

2 Tel.: +90-232-498-6612; fax: +90-232-498-6505.
}

predict the compressive strength development of concrete based on measuring the adiabatic heat signature to estimate the degree of hydration. Prediction modelling studies, like regression and other mathematical models, were also proposed $[9,10]$. Recently, artificial neural networks (ANNs) were used to create a prediction model $[11,12]$.

The benefits of using ANN models are the ease of application, robustness, etc. They are, however, black box models. They do not yield an explicit relation between input and output variables, which makes them more difficult to interpret. All that the model offers is a weight matrix that defines the weights of interlayer connections, which are optimized after thousands of iterations. Considering the type of data used in cement strength modelling, fuzzy logic may prove to be a better modelling tool. The collected plant data are always associated with some error, which makes the fuzzy approach more suitable [13]. First of all, the fuzzy approach provides possible rules relating input variables to the output variable; hence, it is more in-line with human thought. Therefore, plant operators can rapidly develop their own set of rules to test for their fit for the fuzzy model. This makes the fuzzy approach more user friendly. In a previous study, Fa-Liang [13] developed a fuzzy model to predict 
cement strength by feeding the model with the 2-day strength data to predict the 28-day strength. However, the chemical and physical parameters were not considered in that study. Moreover, there is no information on fuzzy rules, membership functions, and defuzzification procedures in that study.

In this article, the chemical and physical parameters of cement mortar were used as a feed to a fuzzy logic model. Process control data from a local cement plant, which were used in a previous publication [11], are employed in this article for model construction. Cement strength testing was performed in accordance with European Standard EN 196-1 [14]. The triangular membership functions and the fuzzy rules were written based on an ANN model created for this purpose.

\section{Fuzzy logic}

A general fuzzy system is presented in Fig. 1. According to Fig. 1, the system has basically four components: fuzzification, fuzzy rule base, fuzzy output engine, and defuzzification.

Fuzzification converts each piece of input data to degrees of membership by a lookup in one or more several membership functions. The key idea in fuzzy logic, in fact, is the allowance of partial belongings of any object to different subsets of a universal set instead of belonging to a single set completely. Partial belonging to a set can be described numerically by a membership function, which assumes values between 0 and 1 inclusive. Intuition, inference, rank ordering, angular fuzzy sets, neural networks, genetic algorithms, and inductive reasoning can be, among many, ways to assign membership values or functions to fuzzy variables. Fuzzy membership functions may take many forms, but in practical applications, simple linear functions, such as triangular ones, are preferable. In this study, the ANN model was used to assign the membership functions for the input variables of alkali, Blaine, $\mathrm{SO}_{3}$, and $\mathrm{C}_{3} \mathrm{~S}$, and the output variable of 28-day cement strength and triangular membership functions were employed for each variable (Fig. 2). The ANN model architecture employed is shown in Fig. 3.

Fuzzy rule base contains rules that include all possible fuzzy relations between inputs and outputs. These rules are expressed in the If-Then format. In the fuzzy approach, there are no mathematical equations and model parameters, and all the uncertainties, nonlinear relationships, and model complications are included in the descriptive fuzzy inference procedure in the form of If-Then statements. There are basically two kind of fuzzy rules: Jantzen [15]. In this study, we constructed the Mamdani-type fuzzy rules, relating input variables to the output variable by the use of the ANN model, and summarized a random selection in Table 1.

Fuzzy inference engine takes into account all the fuzzy rules in the fuzzy rule base and learns how to transform a set of inputs to corresponding outputs. There are basically two kinds of inference operators: minimization $(\mathrm{min})$ and product (prod). Jantzen [15] points out that both methods, in general, work well. In this study, we employed the prod method due to its better performance.

Defuzzification converts the resulting fuzzy outputs from the fuzzy inference engine to a number. There are many defuzzification methods such as centre of gravity (COG; centroid), bisector of area (BOA), mean of maxima (MOM), leftmost maximum (LM), rightmost maximum (RM), etc. $[15,16]$. In this study, we employed the most commonly used centroid method, and for the discrete case, it is expressed as [15]:

$$
K_{\mathrm{x}}^{*}=\frac{\sum_{i} \mu\left(K_{\mathrm{x} i}\right) K_{\mathrm{x} i}}{\sum_{i} \mu\left(K_{\mathrm{x} i}\right)}
$$

where $K_{\mathrm{x}}^{*}$ is the defuzzified output value, $K_{\mathrm{x} i}$ is the output value in the $i$ th subset, and $\mu\left(K_{\mathrm{x} i}\right)$ is the membership value of the output value in the $i$ th subset. For the continuous case, the summations in Eq. (1) are replaced by integrals.

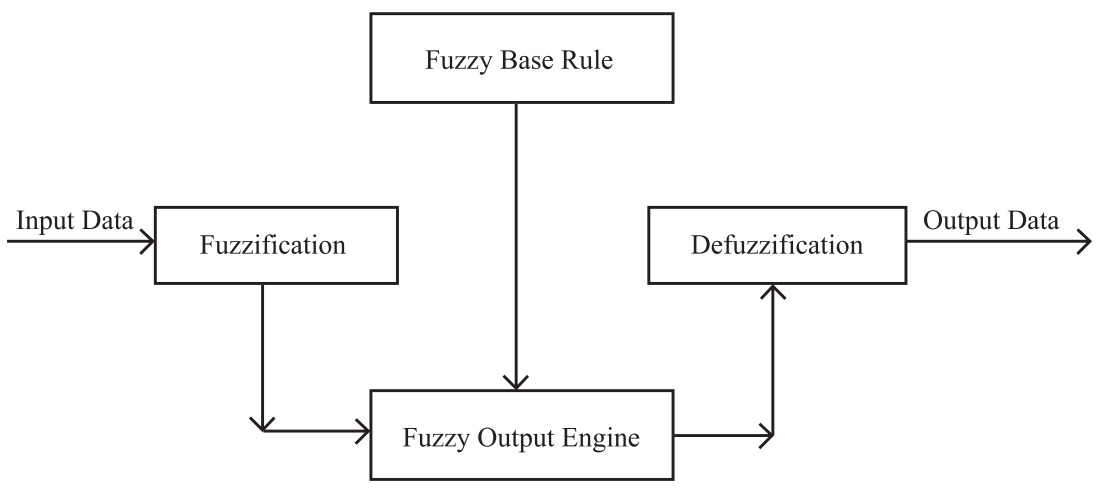

Fig. 1. The fuzzy logic modelling process. 


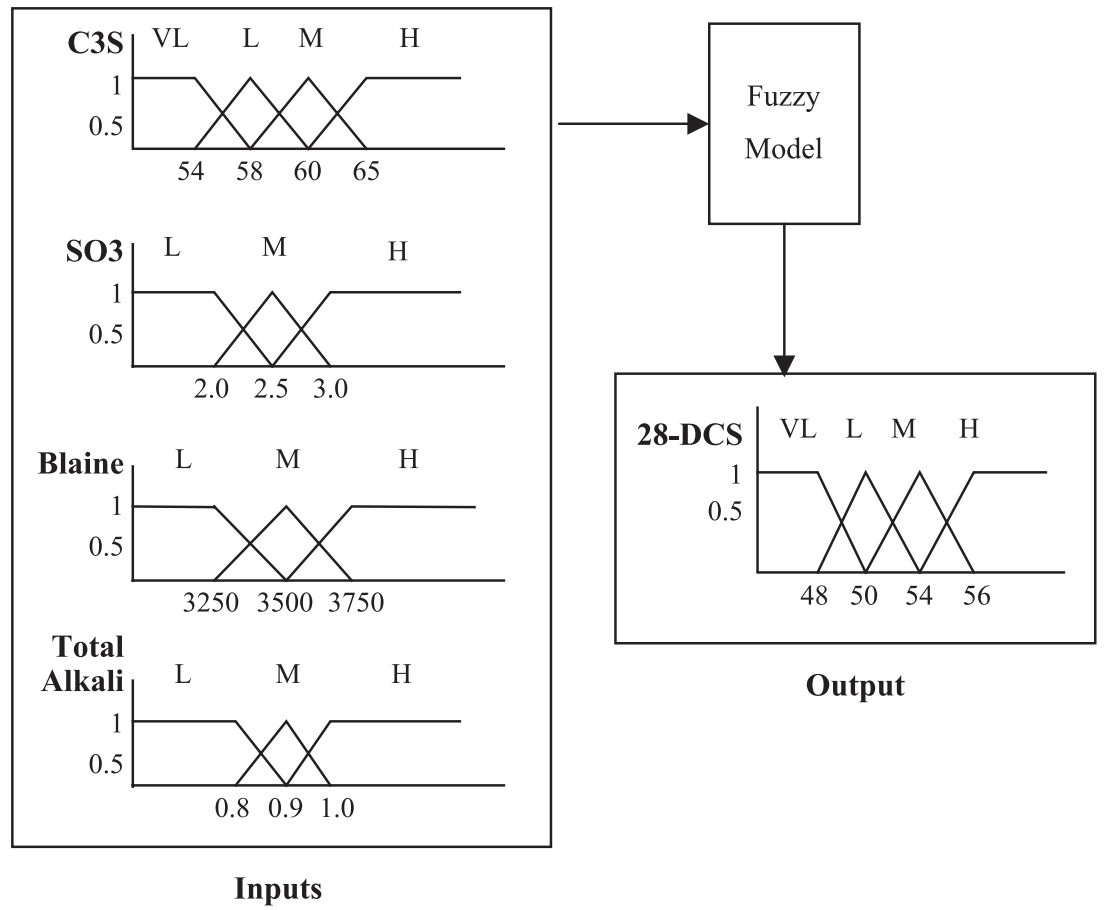

Fig. 2. Membership functions for input and output parameters used for fuzzy modelling.

More details on the fuzzy logic can be obtained from Refs. [15-22].

\section{Model construction}

The original data used in a previous article for ANN modelling were employed in this article for fuzzy model construction. To create the fuzzy rule sets and their membership functions, a new ANN model was created following the same procedures outlined in Ref. [11]. The only exception was that the new ANN model had four input parameters $\left[\begin{array}{lllll}\% & \mathrm{C}_{3} \mathrm{~S}, \% & \mathrm{SO}_{3}, \% & \% \text { total alkali, and }\end{array}\right.$ Blaine $\left.\left(\mathrm{cm}^{2} / \mathrm{g}\right)\right]$ and one output parameter of 28-day compressive strength $\left(\mathrm{N} / \mathrm{mm}^{2}\right)$ as opposed to more than

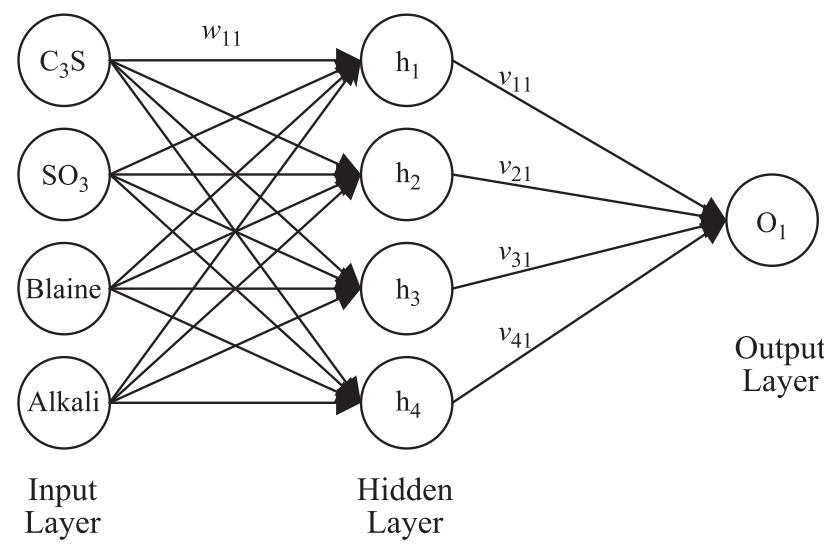

Fig. 3. ANN model architecture.
20 for the previous model. These parameters $\left(\mathrm{C}_{3} \mathrm{~S}, \mathrm{SO}_{3}\right.$, total alkali, and Blaine) were believed to represent the more important factors regarding compressive strength based on the sensitivity analysis done on our previous model. The newly constructed ANN model had three layers: input, hidden, and output. The input and hidden layers had four neurons, while the output layer had only one neuron. Bias term was not used in the training. Learning rate was 0.01 . The model was trained for

Table 1

A random selection of 20 rule sets from the total 108 sets

\begin{tabular}{lllll}
\hline$\% \mathrm{C}_{3} \mathrm{~S}$ & $\% \mathrm{SO}_{3}$ & Blaine & $\%$ Alkali & Strength \\
\hline $\mathrm{L}$ & $\mathrm{M}$ & $\mathrm{L}$ & $\mathrm{M}$ & $\mathrm{M}$ \\
$\mathrm{M}$ & $\mathrm{M}$ & $\mathrm{L}$ & $\mathrm{L}$ & $\mathrm{L}$ \\
$\mathrm{L}$ & $\mathrm{H}$ & $\mathrm{M}$ & $\mathrm{L}$ & $\mathrm{M}$ \\
$\mathrm{L}$ & $\mathrm{L}$ & $\mathrm{H}$ & $\mathrm{M}$ & $\mathrm{VL}$ \\
$\mathrm{VL}$ & $\mathrm{L}$ & $\mathrm{H}$ & $\mathrm{M}$ & $\mathrm{VL}$ \\
$\mathrm{H}$ & $\mathrm{H}$ & $\mathrm{L}$ & $\mathrm{M}$ & $\mathrm{L}$ \\
$\mathrm{VL}$ & $\mathrm{H}$ & $\mathrm{H}$ & $\mathrm{H}$ & $\mathrm{M}$ \\
$\mathrm{VL}$ & $\mathrm{H}$ & $\mathrm{L}$ & $\mathrm{L}$ & $\mathrm{H}$ \\
$\mathrm{H}$ & $\mathrm{H}$ & $\mathrm{M}$ & $\mathrm{M}$ & $\mathrm{M}$ \\
$\mathrm{VL}$ & $\mathrm{M}$ & $\mathrm{H}$ & $\mathrm{H}$ & $\mathrm{L}$ \\
$\mathrm{L}$ & $\mathrm{H}$ & $\mathrm{H}$ & $\mathrm{H}$ & $\mathrm{M}$ \\
$\mathrm{M}$ & $\mathrm{L}$ & $\mathrm{L}$ & $\mathrm{M}$ & $\mathrm{L}$ \\
$\mathrm{M}$ & $\mathrm{H}$ & $\mathrm{L}$ & $\mathrm{M}$ & $\mathrm{M}$ \\
$\mathrm{L}$ & $\mathrm{M}$ & $\mathrm{M}$ & $\mathrm{H}$ & $\mathrm{L}$ \\
$\mathrm{M}$ & $\mathrm{M}$ & $\mathrm{L}$ & $\mathrm{H}$ & $\mathrm{L}$ \\
$\mathrm{VL}$ & $\mathrm{H}$ & $\mathrm{H}$ & $\mathrm{L}$ & $\mathrm{H}$ \\
$\mathrm{L}$ & $\mathrm{M}$ & $\mathrm{H}$ & $\mathrm{L}$ & $\mathrm{M}$ \\
$\mathrm{VL}$ & $\mathrm{M}$ & $\mathrm{M}$ & $\mathrm{H}$ & $\mathrm{L}$ \\
$\mathrm{L}$ & $\mathrm{L}$ & $\mathrm{L}$ & $\mathrm{L}$ & $\mathrm{L}$ \\
$\mathrm{VL}$ & $\mathrm{H}$ & $\mathrm{M}$ & $\mathrm{H}$ & $\mathrm{M}$ \\
\hline
\end{tabular}

VL, very low; L, low; M, medium; H, high. 
20,000 iterations. The reduction in the number of input parameters from 20 to 4 resulted in a slight increase in the percentage testing error, as already expected, for the new ANN model (average absolute error 2.41\%). However, the model was still successful, and we were able to generate the rule sets for the fuzzy model. There were a total of 108 fuzzy rule sets, randomly selected, 20 of which are listed

Table 2

Testing data for comparison of the ANN and the fuzzy logic models

Data used in model construction Comparison of ANN and fuzzy models

$\mathrm{C}_{3} \mathrm{~S} \quad \mathrm{SO}_{3}$ Blaine Alkali Strength Fuzzy ANN \% Fuzzy \% ANN model model error error

$\begin{array}{lllllllll}54.0 & 3.0 & 3530 & 1.1 & 53.9 & 53.3 & 54.2 & 1.1 & 0.5\end{array}$

$\begin{array}{lllllllll}54.8 & 2.9 & 3680 & 0.9 & 51.9 & 54.0 & 55.5 & 4.0 & 6.9\end{array}$

$\begin{array}{lllllllll}57.3 & 2.8 & 3560 & 1.0 & 53.9 & 52.3 & 54.4 & 3.0 & 1.0\end{array}$

$\begin{array}{lllllllll}64.6 & 2.6 & 3850 & 1.0 & 50.8 & 51.2 & 53.4 & 0.8 & 5.1\end{array}$

$\begin{array}{lllllllll}56.9 & 2.7 & 3580 & 0.8 & 54.5 & 53.4 & 54.1 & 2.0 & 0.7\end{array}$

$\begin{array}{lllllllll}61.3 & 2.3 & 3780 & 0.9 & 50.4 & 52.3 & 51.3 & 3.8 & 1.7\end{array}$

$\begin{array}{lllllllll}62.3 & 2.8 & 3640 & 0.9 & 55.4 & 53.3 & 53.4 & 3.8 & 3.5\end{array}$

$\begin{array}{lllllllll}62.4 & 2.8 & 3590 & 0.9 & 58.4 & 53.4 & 53.2 & 8.6 & 8.9\end{array}$

$\begin{array}{lllllllll}64.6 & 2.5 & 4090 & 0.8 & 54.8 & 53.3 & 53.2 & 2.7 & 2.9\end{array}$

$\begin{array}{lllllllll}59.3 & 2.8 & 3500 & 1.1 & 51.8 & 52.4 & 53.7 & 1.2 & 3.7\end{array}$

$\begin{array}{lllllllll}61.8 & 2.7 & 3630 & 1.1 & 51.3 & 52.0 & 53.3 & 1.4 & 3.9\end{array}$

$\begin{array}{lllllllll}61.3 & 3.0 & 3580 & 1.0 & 54.7 & 53.4 & 54.0 & 2.4 & 1.4\end{array}$

$\begin{array}{lllllllll}60.4 & 2.6 & 3680 & 1.0 & 54.1 & 51.3 & 53.3 & 5.2 & 1.4\end{array}$

$\begin{array}{lllllllll}55.6 & 3.1 & 3510 & 1.0 & 54.5 & 53.4 & 54.8 & 2.0 & 0.6\end{array}$

$\begin{array}{lllllllll}62.4 & 2.5 & 3590 & 1.1 & 51.5 & 50.8 & 51.5 & 1.4 & 0.0\end{array}$

$\begin{array}{lllllllll}63.1 & 2.6 & 3540 & 0.9 & 52.1 & 53.3 & 52.5 & 2.3 & 0.9\end{array}$

$\begin{array}{lllllllll}61.2 & 2.7 & 3610 & 0.9 & 51.7 & 53.4 & 53.6 & 3.3 & 3.6\end{array}$

$\begin{array}{lllllllll}55.6 & 2.7 & 3620 & 0.9 & 54.2 & 53.4 & 54.6 & 1.5 & 0.8\end{array}$

$\begin{array}{lllllllll}67.3 & 2.6 & 4020 & 0.8 & 53.8 & 53.3 & 52.4 & 0.9 & 2.6\end{array}$

$\begin{array}{lllllllll}58.7 & 3.0 & 3550 & 0.9 & 51.5 & 53.7 & 54.0 & 4.3 & 4.9\end{array}$

$\begin{array}{lllllllll}65.4 & 2.3 & 3730 & 0.9 & 48.9 & 52.3 & 51.4 & 7.0 & 5.1\end{array}$

$\begin{array}{lllllllll}58.0 & 2.7 & 3420 & 1.0 & 53.2 & 51.9 & 53.7 & 2.4 & 1.0\end{array}$

$\begin{array}{lllllllll}65.0 & 2.5 & 4070 & 0.8 & 54.7 & 53.3 & 53.1 & 2.6 & 3.0\end{array}$

$\begin{array}{lllllllll}62.0 & 2.9 & 3720 & 1.0 & 54.3 & 52.9 & 54.4 & 2.6 & 0.2\end{array}$

$\begin{array}{lllllllll}61.4 & 2.7 & 3840 & 0.9 & 52.5 & 53.4 & 54.4 & 1.7 & 3.5\end{array}$

$\begin{array}{lllllllll}63.5 & 2.5 & 3540 & 1.0 & 51.3 & 50.7 & 52.4 & 1.2 & 2.1\end{array}$

$\begin{array}{lllllllll}62.8 & 2.3 & 3580 & 0.9 & 51.1 & 52.2 & 51.4 & 2.2 & 0.5\end{array}$

$\begin{array}{lllllllll}56.4 & 3.0 & 3370 & 1.1 & 52.5 & 53.5 & 54.3 & 1.9 & 3.5\end{array}$

$\begin{array}{lllllllll}62.8 & 3.0 & 3750 & 1.1 & 54.1 & 55.3 & 54.6 & 2.2 & 1.0\end{array}$

$\begin{array}{lllllllll}58.9 & 3.0 & 3540 & 1.0 & 53.5 & 53.6 & 54.4 & 0.2 & 1.6\end{array}$

$\begin{array}{lllllllll}62.3 & 2.5 & 3910 & 0.9 & 53.6 & 53.2 & 53.3 & 0.7 & 0.6\end{array}$

$\begin{array}{lllllllll}57.7 & 2.7 & 3480 & 1.0 & 55.4 & 51.7 & 53.8 & 6.7 & 2.9\end{array}$

$\begin{array}{lllllllll}55.8 & 3.1 & 3420 & 0.9 & 53.7 & 53.6 & 54.0 & 0.2 & 0.6\end{array}$

$\begin{array}{lllllllll}55.9 & 2.8 & 3620 & 1.0 & 55.6 & 52.4 & 54.4 & 5.8 & 2.2\end{array}$

$\begin{array}{lllllllll}60.7 & 2.8 & 3740 & 1.1 & 55.2 & 52.2 & 53.9 & 5.4 & 2.4\end{array}$

$\begin{array}{lllllllll}59.3 & 2.5 & 3750 & 1.1 & 55.5 & 50.7 & 50.7 & 8.6 & 8.6\end{array}$

$\begin{array}{lllllllll}60.8 & 2.2 & 3520 & 1.1 & 49.8 & 50.4 & 49.0 & 1.2 & 1.6\end{array}$

$\begin{array}{lllllllll}60.7 & 3.0 & 3840 & 0.9 & 55.6 & 54.3 & 54.8 & 2.3 & 1.5\end{array}$

$\begin{array}{lllllllll}63.2 & 2.5 & 4010 & 0.9 & 52.1 & 53.3 & 53.3 & 2.3 & 2.3\end{array}$

$\begin{array}{lllllllll}59.3 & 2.6 & 3450 & 1.0 & 51.6 & 51.4 & 53.2 & 0.4 & 3.0\end{array}$

$\begin{array}{lllllllll}65.8 & 2.6 & 4050 & 0.9 & 53.0 & 53.3 & 53.6 & 0.6 & 1.1\end{array}$

$\begin{array}{lllllllll}57.4 & 2.5 & 3390 & 1.1 & 50.5 & 50.8 & 50.8 & 0.6 & 0.6\end{array}$

$\begin{array}{lllllllll}62.0 & 2.4 & 3490 & 1.0 & 54.0 & 50.7 & 51.6 & 6.1 & 4.5\end{array}$

$\begin{array}{lllllllll}59.7 & 2.2 & 3890 & 1.0 & 52.1 & 50.4 & 49.6 & 3.3 & 4.8\end{array}$

$\begin{array}{lllllllll}56.8 & 2.7 & 3620 & 1.0 & 53.8 & 51.8 & 53.8 & 3.7 & 0.0\end{array}$

$\begin{array}{lllllllll}61.7 & 2.4 & 3630 & 0.9 & 53.6 & 52.6 & 52.2 & 1.9 & 2.6\end{array}$

$\begin{array}{lllllllll}63.6 & 2.8 & 3680 & 0.9 & 53.0 & 53.4 & 53.2 & 0.8 & 0.4\end{array}$

$\begin{array}{lllllllll}61.6 & 2.8 & 3630 & 1.1 & 53.5 & 52.4 & 53.9 & 2.1 & 0.8\end{array}$

$\begin{array}{lllllllll}64.9 & 2.4 & 3900 & 1.0 & 49.9 & 50.6 & 51.6 & 1.4 & 3.4\end{array}$

\begin{tabular}{lllllllll}
61.0 & 2.8 & 3700 & 0.9 & 54.2 & 53.6 & 54.1 & 1.1 & 0.2 \\
\hline
\end{tabular}

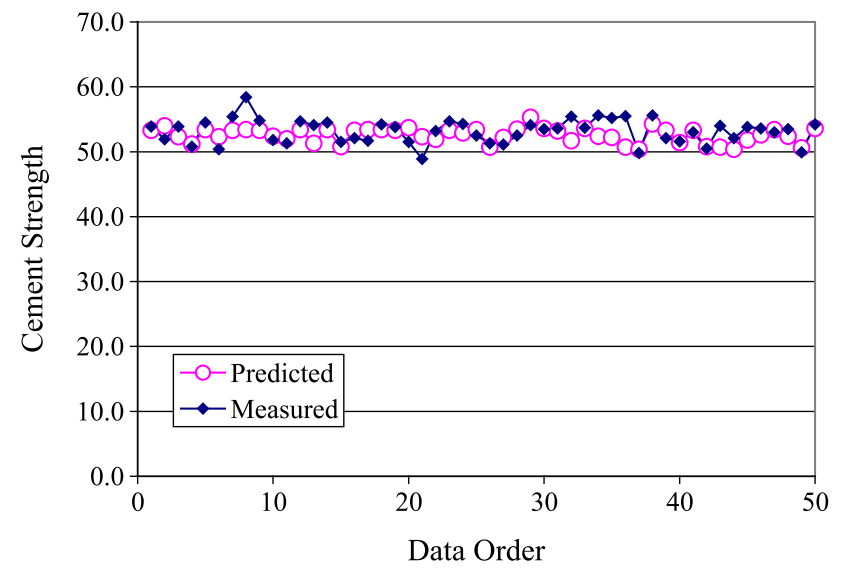

Fig. 4. Comparison of the observed cement strength and predicted quantities by the fuzzy model.

in Table 1, and the constructed membership functions are shown in Fig. 2.

\section{Model application}

The developed fuzzy logic-based model was applied to predict 50 sets of the 28-day cement strength data obtained from a local cement plant in Izmir, Turkey (Table 2). The total number of data sets was 150 , but a randomly selected 50 were used for model testing. The same data sets were also used in a previous study [11]. We devised the fuzzy logic-based algorithm model by using the fuzzy logic toolbox in Matlab. The prod and centroid methods were employed as the inference operator and defuzzification methods, respectively. The prediction results of the measured data by the developed fuzzy model and the ANN model are presented in Table 2 and Fig. 4. According to Table 2 and Fig. 4, the fuzzy model predicts the measured data successfully, and its performance is comparable with that of ANNs. To have an objective comparison of the performance of the models, the error measures of the root mean square error (RMSE) and the mean absolute error (MAE) were computed for each model, and these are summarized in Table 3. As can be seen in Table 3, the error measures for the fuzzy model are comparable with those of the ANN model. The latter, developed for the purpose of fuzzy rule creation, was produced with an average absolute percentage error of $2.41 \%$ (RMSE 1.70 ). This quantity was higher than the $2.24 \%$ (RMSE 1.53 ) achieved in Ref. [11] for 20 input parameters. This increase in the error was a

Table 3

Error comparisons for the two models

\begin{tabular}{llll}
\hline Type of model & & Fuzzy & ANN \\
\hline RMSE & & 1.84 & 1.70 \\
MAE & Min & 0.19 & 0.02 \\
& Ave & 2.69 & 2.41 \\
& Max & 8.65 & 8.91 \\
\hline
\end{tabular}


result of parameter elimination from 20 to 4. Variation caused by eliminated parameters was added to total error variance. The fuzzy model, perhaps, could have produced lower percentage errors than $2.69 \%$ (RMSE 1.84 ) if it had been constructed with more than four input parameters. However, such a slight improvement might not have been worth the effort to create a very complicated fuzzy model.

The strength measurements of brittle materials, like cement mortar, are always associated with a distribution. Such measurements never provide the same exact strength quantity. Therefore, the fuzzy approach is well suited for such samples. Another advantage of the fuzzy logic is that all the rules are written verbally, much like human thought. ANN models, on the other hand, are black box models, not immediately visible to the user. Plant operators may easily adapt to the verbal rule creation process.

\section{Conclusions}

A fuzzy logic model was created to predict the 28-day cement strength. Input parameters used in model creation process included $\mathrm{C}_{3} \mathrm{~S}, \mathrm{SO}_{3}$, total alkali, and surface area (Blaine). The model was created from a local cement plant process control data. A four-parameter ANN model was used to produce the fuzzy rule sets in the fuzzy model building stage. Successful predictions of the observed cement strength by the model indicate that fuzzy logic could be a useful modelling tool for engineers and research scientists in the area of cement and concrete.

Although the fuzzy model yielded slightly higher error than ANN, its explicit nature may grant its use by cement professionals for prediction purposes. The cement data are always associated with some measurement errors, which makes the fuzzy approach more suitable than the ANN is in that regard.

The successful predictions of the 28-day cement strength data by the fuzzy model indicate that the employed prod activator and centroid defuzzification methods are appropriate.

\section{Acknowledgements}

The authors thank the Turkish Cement Manufacturers' Association (TCMA) for providing financial support to $\mathrm{Mr}$. Sever Can.

\section{References}

[1] H.F.W. Taylor, Cement Chemistry, Academic Press, London, 1990.

[2] D.P. Bentz, Three-dimensional computer simulation of Portland cement hydration and microstructure development, J. Am. Ceram. Soc. 80 (1) (1997) 3-21.

[3] Y.M. Zhang, T.J. Napier-Munn, Effects of particle size distribution, surface area and chemical composition on Portland cement strength, Powder Technol. 83 (3) (1995) 245-252.

[4] B. Osbaeck, V. Johansen, Particle size distribution and rate of strength development of Portland cement, J. Am. Ceram. Soc. 72 (2) (1989) 197-201.

[5] N.J. Carino, The maturity method: theory and application, Cem. Concr. Aggreg. 6 (2) (1984) 61-73.

[6] S. Tsivilis, S. Tsimas, A. Benetatou, E. Haniotakis, Study on the contribution of fineness on cement strength, ZKG, (43) (1990) 26-29.

[7] B. Osbaeck, The influence of alkalis on the strength properties of Portland cement, ZKG, (32) (1979) 72-77.

[8] F.F. Radjy, D.W. Vunic, Heat signature testing of concrete, Proceedings of Structural Materials Technology-An NDT Conference (Atlantic City, NJ, 1994), Techomic Publishing, Lancaster, PA, 1994, pp. $8-15$.

[9] S. Tsivilis, G. Parissakis, A mathematical-model for the prediction of cement strength, Cem. Concr. Res. 25 (1995) 9-14.

[10] C.E. de Siquera Tango, An extrapolation method for compressive strength prediction of hydraulic cement products, Cem. Concr. Res. 28 (7) (1998) 969-983.

[11] S. Akkurt, S. Ozdemir, G. Tayfur, B. Akyol, The use of GA-ANNs in the modelling of compressive strength of cement mortar, Cem. Concr. Res. 33 (2003) 973-979.

[12] M. Sebastia, I.F. Olmo, A. Irabien, Neural network prediction of unconfined compressive strength of coal fly ash-cement mixtures, Cem. Concr. Res. 33 (2003) 1137-1146.

[13] G. Fa-Liang, A new way of predicting cement strength-fuzzy logic, Cem. Concr. Res. 27 (1997) 883-888.

[14] European Committee for Standardization (CEN), Methods of testing cement: Part 1. Determination of strength, European Standard EN 196-1.

[15] J. Jantzen, Design of fuzzy controllers, Technical Report (No:98E864) Department of Automation, Technical Univ. of Denmark, 1999.

[16] Z. Sen, Fuzzy Modeling in Engineering, Class Notes, Civil Engineering Faculty, Istanbul Technical University, Istanbul, Turkey, 1999 (in Turkish).

[17] G.J. Kilir, T.A. Fogel, Fuzzy Sets, Uncertainty and Information, Prentice-Hall, New York, 1988.

[18] B. Kosko, Fuzzy Thinking: The New Science of Fuzzy Logic, Hyperion, New York, 1992.

[19] L. Zadeh, J. Kacprzyk (Eds.), Fuzzy Logic for the Management of Uncertainty, Wiley, New York, 1992.

[20] F.M. McNeill, E. Thro, Fuzzy Logic: A Practical Approach, Hyperion, New York, 1994.

[21] T. Munakata, Fundamentals of the New Artificial Intelligence: Beyond Traditional Paradigms, Springer-Verlag, New York, 1998.

[22] Z. Sen, Fuzzy algorithm for estimation of solar irradiation from sunshine duration, Sol. Energy 63 (1) (1998) 39-49. 